\title{
Aproximación bibliométrica a las contribuciones de Hope A. Olson en el campo de la organización del conocimiento
}

Bibliometric approach to the contributions of Hope A. Olson to Knowledge Organization

\section{María Camila Restrepo FeRnÁNDEZ}

Colombia, camila0330.maria@gmail.com

\begin{abstract}
Resumen
Se presenta la trayectoria académica de Hope A. Olson, cuya producción bibliográfica se caracteriza por una marcada crítica hacia los principios de universalidad y jerarquía presentes en las clasificaciones documentales. Para caracterizar su producción se analizaron sus publicaciones indexadas en Scopus hasta 2015 y, posteriormente, se procesó toda la información por medio de la metodología bibliométrica CAMEO con la asistencia de Pajek, VOSviewer y Nvivo. El resultado de la investigación es una caracterización reticular de las contribuciones teóricas de la autora.
\end{abstract}

Palabras clave: Olson, Hope A. Organización del conocimiento. Clasificación documental. Lenguajes documentales. Clasificación Decimal Dewey.

\section{Introducción}

El trabajo de Hope A. Olson versa sobre la aplicación de teorías y metodologías feministas, posestructuralistas y poscolonial en el campo de la organización del conocimiento (OC), desde el redil bibliotecológico, con énfasis en los sistemas de clasificación.

A lo largo de su obra, Olson explora la presunta necesidad de usar lenguajes universales para representar o nombrar el conocimiento con el objetivo de ser recuperado, explica las consecuencias del uso de estos lenguajes y propone técnicas para un cambio paulatino en la representación del conocimiento en los catálogos de las bibliotecas, percibiendo como un asunto problemático la universalización en la representación y organización del conocimiento.

Olson considera que tal como se representa el conocimiento, las bibliotecas fungen como espejos de la marginalización y exclusión de las sociedades a las que sirven, razón que motiva a que su trabajo en $\mathrm{OC}$ se apoye en discursos teóricos, ya mencionados al inicio, que se oponen a la universalidad en las ciencias.

Sus publicaciones, entre las que se encuentran 3 libros completos, 33 capítulos de libro y más de

\begin{abstract}
This research presents the academic trajectory of Hope A. Olson, whose bibliographic production is characterized by a marked criticism of the principles of universality and hierarchy present in library classifications. In order to characterize the academic production, its publications indexed in Scopus up to 2015 were taken as a center of analysis and all the information was then processed through the bibliometric methodology CAMEO with the assistance of Pajek, VOSviewer and Nvivo. The result of the research is a reticulated characterization of the author's theoretical contributions.
\end{abstract}

Keywords: Olson, Hope A. Knowledge Organization. Classification. Library classification. Indexing language. Decimal Dewey Classification.

40 artículos publicados desde 1991, validan las contribuciones de Olson como un cúmulo importante en el campo de estudio de OC, así mismo sus intersecciones con los estudios de género y las Ciencias Sociales enriquecen su trabajo.

Revisitar el trabajo académico de Hope A. Olson posibilita: ver el impacto que ha tenido en otros autores, visibilizar nuevos autores con enfoques teóricos y metodológicos en su misma línea investigativa y evidenciar el poder de las clasificaciones y la indización como mecanismos reproductores de exclusión (en determinados casos), por eso se hace categórico revisar su trabajo.

Así lo prueba el número A Festschrift for Hope A. Olson (2016) de la revista Knowledge Orgatization, en el que una polifonía de voces, compuesta por especialistas reconocidos en OC, aborda y discute el enfoque teórico y metodológico, así como las cuestiones éticas sobre OC presentes en su obra. Los autores del número conmemorativo, a modo grosso, resaltan la labor de Olson al proveer al campo de OC de un suelo epistemológico renovado, alejado de enfoques tradicionales predominantes en el campo. De los trabajos compilados en el número en mención, sobresale un análisis infométrico (Dietmar, 2016, p. 331-337) 
elaborado a partir de citas recolectadas en Google Scholar y Thomson Reuters Web of Science, estudio que concluye en la afirmación de la influencia que puede provocar un individuo, en el caso particular Olson, en el campo y sus investigadores. Otra estudio que expone la relevancia de Olson es Alfaya Lamas (2012) quien califica como representativa la investigación de Olson sobre género y sistemas de organización de conocimiento.

Dentro de este contexto, las inquietudes y cuestionamientos deben dirigirse al futuro de investigación y formación en OC, no sin antes revisar a aquellos autores indispensables para aproximarse a respuestas que abran aún más preguntas de las existentes. Los autores que contribuyen al fortalecimiento de la organización del conocimiento son tantos como diversos por los paradigmas y enfoques que emplean. Autores como Hjørland, Dahlberg, San Segundo Manuel, Cabré, Smiraglia, Izquierdo, Guimarães, Olson (Oliveira, Gracio, \& Silva, 2010), entre otros, han acumulado un trabajo valioso y en conjunto heterogéneo, por lo que estudiar a cualquiera de ellos mediante la aplicación de estudios egocéntricos contribuiría benéficamente a la OC como campo de conocimiento.

El propósito de la investigación tuvo tres ejes: identificar los referentes teóricos sobre los que Olson sustenta su trabajo académico, caracterizar los autores que citan las obras de Olson indexadas en Scopus como base para su producción, identificando sus campos disciplinares y procedencia institucional como vía para aproximarse al impacto del trabajo académico de la autora y establecer las relaciones de Olson con otros autores del campo de la organización de conocimiento y conexos, mediante la identificación de las obras en coautoría.

\section{Método}

La investigación se basa en un enfoque cualitativo, desde el que se pretende explorar el trabajo académico de Hope A. Olson teniendo como insumo principal la producción indexada en Scopus hasta 2015, empleando la metodología CAMEO, que aunque su autor la denomine 'metodología' en este proyecto su empleo es netamente instrumental. La producción de Olson que conforma el universo finito de análisis se seleccionó bajo un muestreo por conveniencia, esto es, un tipo de muestreo no probabilístico, esta clase de muestreo ampara lo aleatorio del periodo temporal seleccionado, permitiendo explorar con mayor rapidez, facilidad y economía (Páramo, 2013) la producción de Olson. La muestra se abordó desde un estudio exploratorio, este método permite tener un acercamiento cualitativo a los datos extraídos por la aplicación de los CAMEOs y a la descripción relacional de Olson en el campo de la OC.

Bajo el enfoque, método e instrumento descritos, se realizó la investigación en tres fases, la primera de ellas avocada a la lectura y revisión de la bibliografía de la autora, la segunda a la aplicación de CAMEO y Pajek y una última fase para el análisis de los resultados.

Characterizations Automatically Made and Edited Online o CAMEO por sus siglas en inglés, es una técnica de visualización de información científica creada por Howard White, diseñada para crear perfiles bibliométricos, dichos perfiles pueden corresponder a un autor, es decir, su objetivo es crear redes egocéntricas centradas en un autor cuya utilidad es ofrecer una breve caracterización de los autores a partir de su producción científica, en el caso de las redes centradas en sujetos CAMEO posibilita la creación de cuatro tipo de perfiles: citation identity, todos los autores citados por el autor focal; citation image-maker, todos los autores que citan al autor focal; citation image, autores cocitados con el autor focal; y co-authors, coautores del autor focal.

Los cuatro perfiles permiten caracterizar a un autor y su entorno de producción más cercano, obteniendo información sobre sus principales campos de interés y los lazos que tiene en el ámbito académico por medio de la identificación de aquellos que cita, lo citan, coautores y niveles de cocitación.

White publicó la metodología CAMEO en 2001 en el $N^{\circ} .51$ de Scientometrics, en el artículo especificó que la metodología debe ser aplicada en Web of Science debido a que el uso de las aplicaciones Scisearch y el software Dialog era imperativo para obtener de manera automática los perfiles, actualmente la metodología puede aplicarse en otras bases de datos con igual éxito que en Web of Science, mediada por otras herramientas bibliométricas. Aunada a la propuesta metodológica de White, se consideraron las contribuciones de Ajiferuke \& Wolfram (2010) como referentes para la etapa de análisis de los resultados.

La investigación en curso aplicó tres perfiles de CAMEO: citation identity, citation image-maker y citation image para caracterizar la producción de Olson, para ello se empleó la base de datos Scopus en la que se albergan 26 artículos de Olson publicados entre 2000-2015 (Ver bibliografía).

Los artículos fueron extractados de la base de datos con la siguiente fórmula de búsqueda: 
AUTHOR-NAME ( olson AND h. AND a. ) AND PUBYEAR > 1999 AND PUBYEAR < 2015.

De los artículos hallados se encontraron 177 artículos publicados bajo el mismo periodo temporal que citan alguna de las veintiséis publicaciones; los artículos y las citas fueron el insumo principal para la elaboración de las gráficas y tablas que están registradas en el tercer apartado del documento en lectura.

Para la construcción de los gráficos se empleó Pajek, un programa de software para el análisis y gráfica de redes ampliamente usado en los estudios bibliométricos que manejan grandes volúmenes de información, su uso es gratuito y la creación de redes es automática. Con Pajek se puede elaborar: genealogías, flujos de datos de programas, bibliografías, redes de citaciones, entre otros. La función de Pajek es soportar la abstracción mediante factorialización de grandes redes en diversas redes de inferior tamaño susceptibles de ser tratadas con métodos más sofisticados; proporcionar herramientas potentes para visualizar estas redes e implementar una selección de algoritmos eficientes para análisis de grandes redes.

Pajek fue crucial para la investigación, porque permitió graficar las redes de Olson de manera automática y sin costo. Para hacerlo se exportaron los resultados obtenidos después de aplicar el parámetro de búsqueda, seleccionando all available information en formato .RIS. El archivo Scopus.ris se colocó en una carpeta con el programa Scopus.exe disponible en <http://www.leydesdorff.net/scopus/index.htm> y al procesar la información se generaron tres nuevas bases de datos: Los títulos en TI. DBF, autores en AU.DBF y referencias en CR.DBF.

Para la graficación se importaron las listas relacionales desde un texto plano al programa Pajek disponible en <http://vlado.fmf.uni-lj.si/pub/networks/pajek/>. Las gráficas son mapas de redes donde los puntos o nodos son los elementos y las líneas, las relaciones. El tamaño de los nodos representa además la cantidad de relaciones que tiene cada nodo, conocido en el análisis de redes como grado de centralidad. En todas las redes la ruta para obtener la centralidad de grado: en el panel central se seleccionó Network/create vector/centrality/degree/all.

Inicialmente el programa Pajek generó redes de dos modos: a) dónde se relacionan los artículos con alguno de los otros parámetros, en todos los casos se transformaron a redes de un nodo, y $b$ ) dónde los elementos se relacionan con los de su mismo tipo (autores con autores, palabras con palabras, referencias con referencias). Para rea- lizar el cambio se siguió la siguiente ruta: Network/2-mode network/2-mode to 1-mode/columns. Finalmente, las gráficas fueron exportadas desde Pajek a VOSviewer disponible en $<$ http://www.vosviewer.com/> para mejorar el aspecto gráfico de la red, aplicativo de uso libre desarrollado por la Universidad de Leiden. Los resultados de la aplicación de Pajek se presentan en el siguiente apartado del texto.

\section{Resultados}

Los resultados se presentan reticularmente en Red de autores citados, Red de autores que citan, Red coautoría y Redes semánticas.

\subsection{Red de autores citados por Olson} en los artículos 2000-2015

En los 26 artículos de Olson hay 693 referencias, para un promedio de 27 referencias por artículo. En ellas se citan a 382 autores incluyendo a OIson, y exceptuando la autocitación hay una baja redundancia en las referencias, A continuación, se presenta el listado de los autores referenciados como mínimo 3 veces.

\begin{tabular}{llll}
\hline Autores & fi & Autores & $f i$ \\
\hline Olson, H.A & 47 & Fraiser, M & 3 \\
\hline Cutter, C.A & 9 & Gorman, M & 3 \\
\hline Dewey, M & 9 & Green, R & 3 \\
\hline Markey, K & 5 & Hegel, G.W.F & 3 \\
\hline Mehra, B & 5 & Hildreth, C.R & 3 \\
\hline Nunberg, G & 5 & Hill, J.S & 3 \\
\hline Swanson, D.R & 5 & Hjorland, B & 3 \\
\hline Chan, L.M & 4 & livonen, M & 3 \\
\hline Cleverdon, C.W & 4 & Kipp, M.E.I & 3 \\
\hline Harris, W.T & 4 & Kublik, A & 3 \\
\hline Intner, S.S & 4 & Maron, M.E & 3 \\
\hline Smiraglia, R.P & 4 & Martinez-Ávila, D. & 3 \\
\hline Svenonius, E & 4 & Miksa, F & 3 \\
\hline Weinberg, B.H & 4 & Ranganathan, S.R & 3 \\
\hline Wiegand, W.A & 4 & Sayers, W.C.B & 3 \\
\hline Avram, H.D & 3 & Spivak, G.C & 3 \\
\hline Ellis, D & 3 & Taylor, A.G & 3 \\
\hline Fister, B & 3 & Wolfram, D & 3 \\
\hline Foucault, M & 3 & Yee, M.M & 3 \\
\hline
\end{tabular}

Tabla I. Autores citados por Olson

67 autores son citados en dos artículos diferentes $(17,5 \%$ del total de autores) y $277(72,5 \%)$ una 
única vez. La relación es susceptible de ser representada en la red, si dos o más autores figuran en las referencias de un mismo artículo, debido a que el autor los utiliza para una misma investigación. En los artículos de la muestra hay veintisiete referencias por artículo, lo que quiere decir que cada autor referenciado tiene en promedio veintiséis relaciones con otros autores. Cuando de los 27 autores referenciados hay un par de ellos que aparecen juntos en otros artículos indicaría que la relación entre su investigación podría ser más grande, a mayor co-ocurrencia mayor similaridad entre los trabajos académicos de los autores. El total de relaciones entre referencias fue de 597, generando una red densa e ilegible, por lo que se realizaron operaciones adicionales para transformarla en una red con autores referenciados en 2 o más artículos.

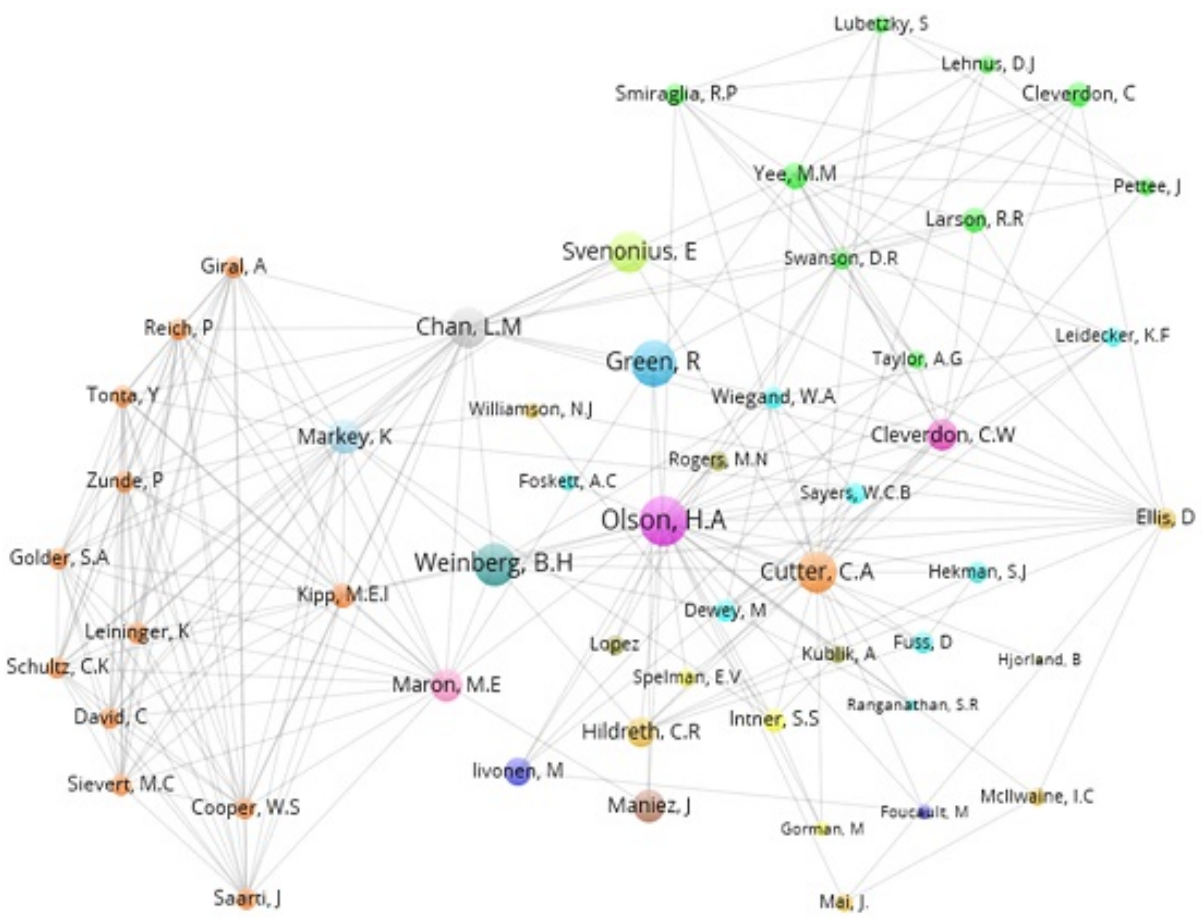

Figura 1. Red de principales autores citados por Olson

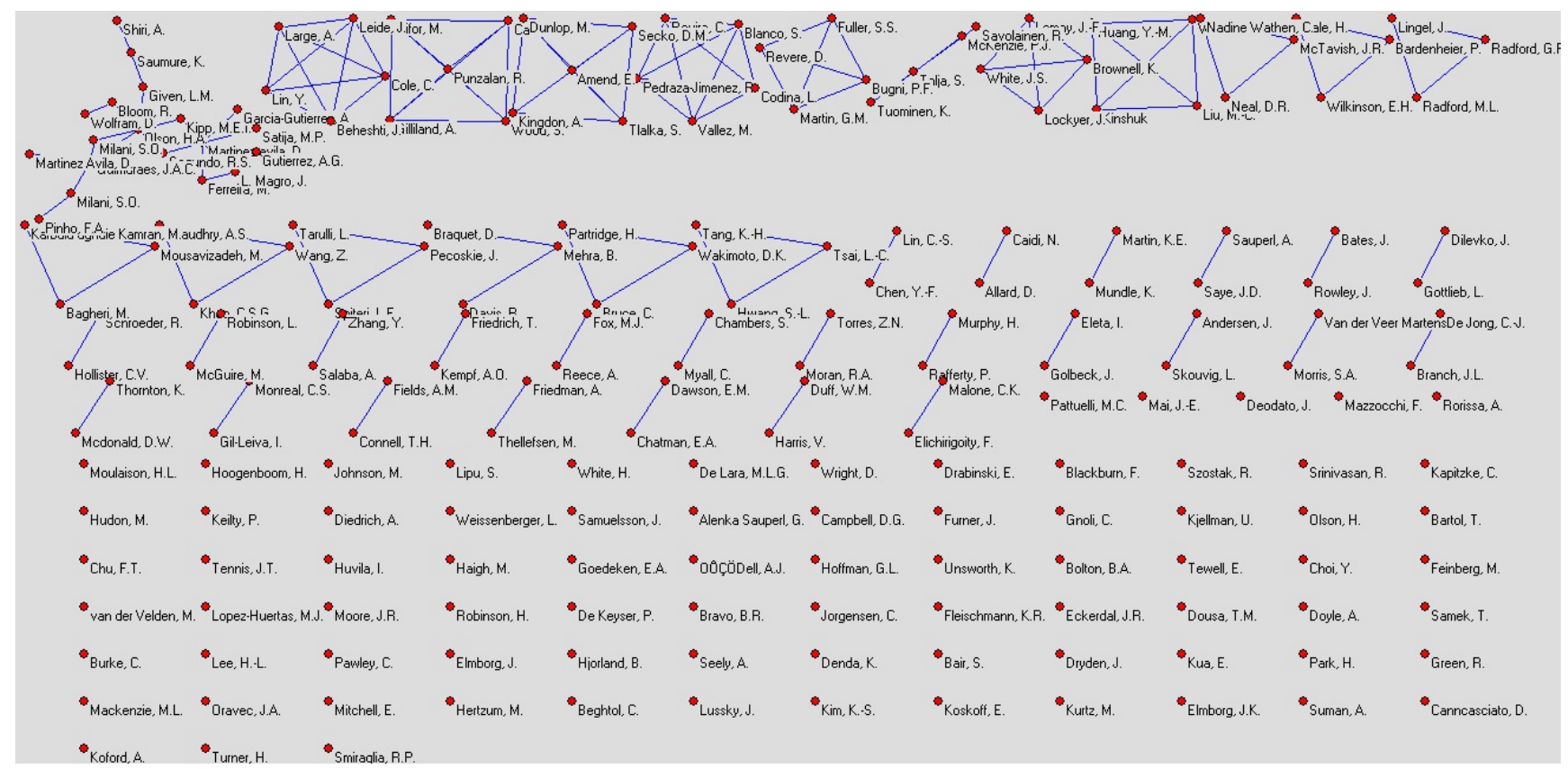

Figura 2. Red total de autores que citan a Olson 


\subsection{Red de autores que citan a Olson 2000-2015}

En total se hallaron 212 autores que citan a Olson, incluyéndola; 80 son autores únicos y 59 escribieron en co-autoría. Es relevante aclarar que, exceptuando la gran red que hay en la parte superior izquierda de la Figura 3, los grupos de autores que figuran en la gráfica escribieron cada uno un solo artículo. Para graficar de forma más clara, sólo se destacó la red de la parte superior izquierda de la Figura 2 (en la página anterior), para ello se ejecutó la ruta: Network/components/weak y se seleccionó que identificara la red con más de diez autores, luego al seleccionar Operation/extract subnetwork y seleccionar "1" se eliminó a todos los autores que no hacen parte de la red principal, dando como resultado la Figura 3, presentada a continuación:

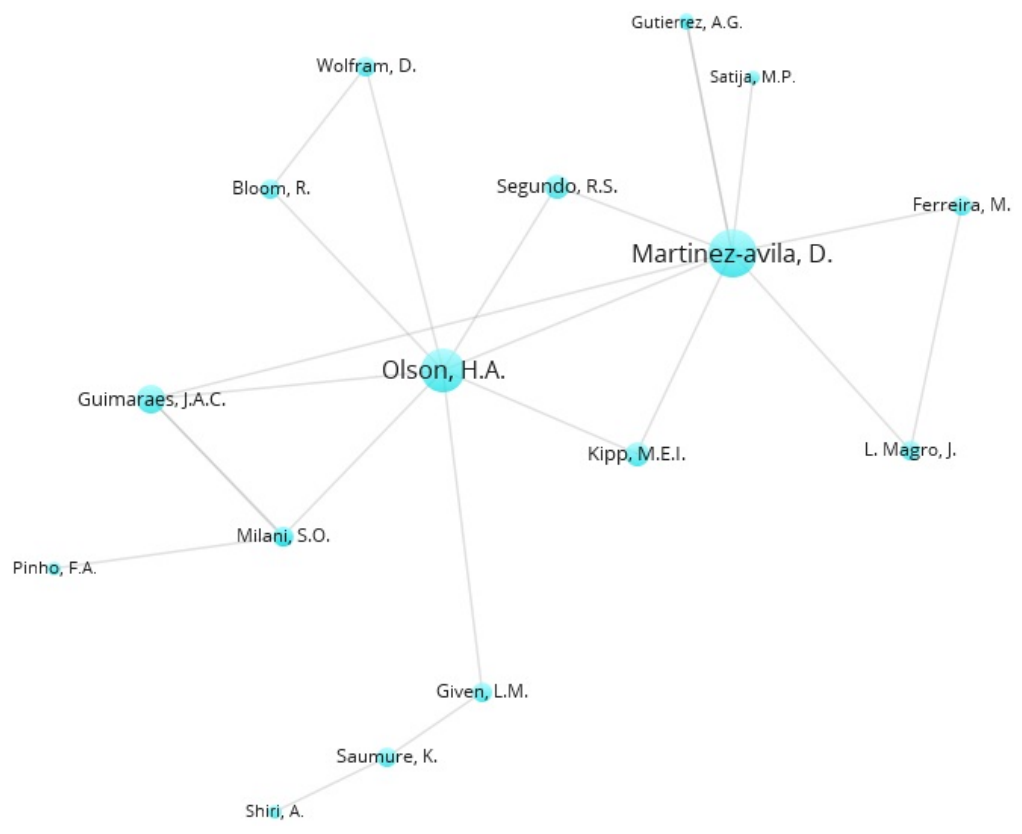

Figura 3. Red de principales de autores que citan a Olson

\subsection{Red de coautoría $2000-2015$}

Esta es una red egocéntrica, lo que explica la centralidad del nodo 'Olson', los demás nodos son periféricos, cada nodo numerado representa a uno de los veintiséis artículos de la muestra, la numeración fue aleatoria. Cada línea relaciona al artículo con los autores que lo escribieron, así por ejemplo el artículo cuatro sólo fue escrito por Olson, mientras que el artículo diecinueve fue escrito por Clevette, Ward, Kublik y Olson.

Se tomó la red de relaciones entre autores y artículos y se eliminaron los artículos de la gráfica para que la red fuera sólo de relaciones entre autores, sin embargo, las líneas siguen representando la co-autoría en los mismos artículos.

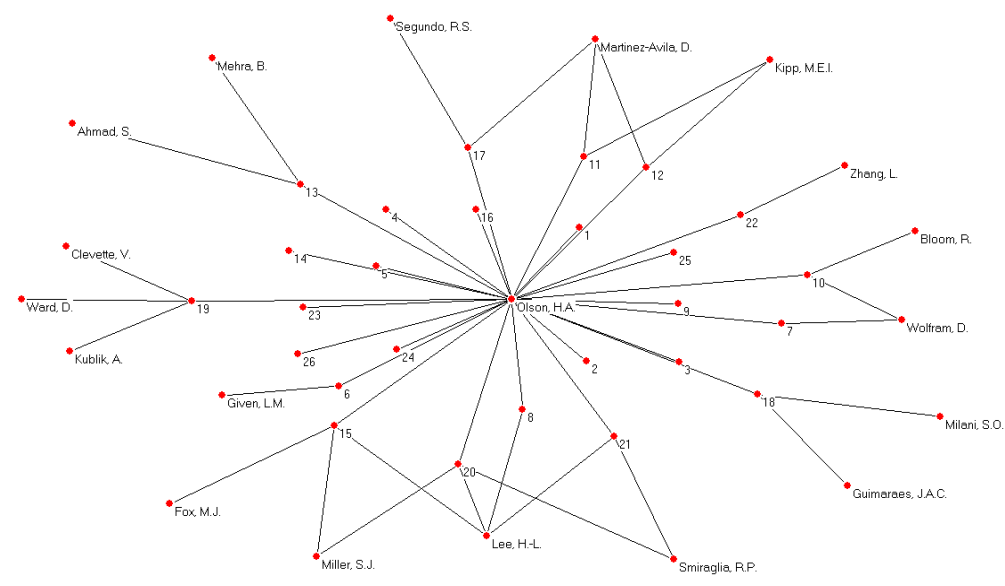

Figura 4. Red de Coautoría

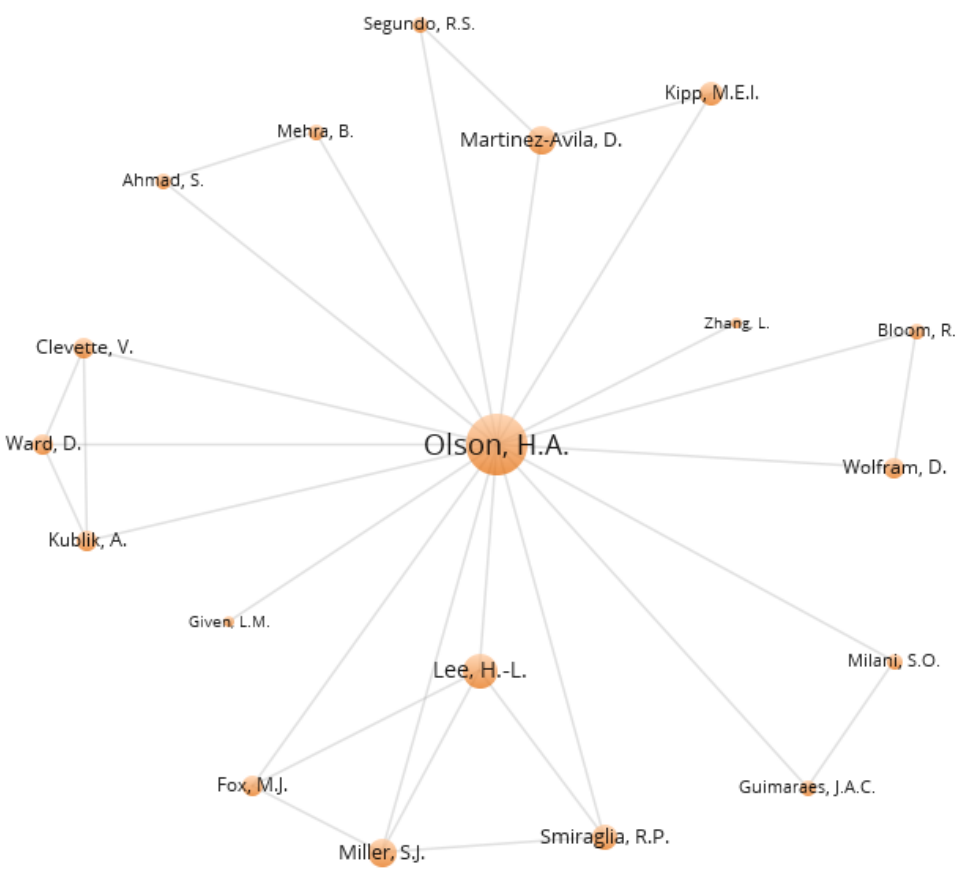

Figura 5. Red de Coautoría

\subsection{Red semántica}

En los 26 artículos de Olson hay 87 palabras clave, de estas 75 aparecen en un solo artículo, y sólo doce tuvieron aparición en al menos dos artículos. En la Tabla II, en la página siguiente, se presentan las palabras clave que se utilizaron en dos o más artículos. 
A pesar de que la baja continuidad entre las palabras, sí se presentan muchas relaciones porque cada palabra se relaciona con las otras palabras clave de su mismo artículo. En la gráfica de redes se puede ver claramente subgrupos de temas relacionados entre sí densamente, que corresponderían a las palabras de un mismo artículo y a unas palabras puente como son las de recurrencia en varios artículos. Para que Pajek identificara los nodos que hacen parte de un mismo campo temático por sus relaciones mutuas se ejecutó la ruta: Network/create partition/communities/Louvain Method/Multi-level coarsening+multi-level refinement, con el parámetro de resolución de ' 1 ', dando como resultado la Figura 6.

\begin{tabular}{ll}
\hline Palabras clave & $f i$ \\
\hline Classification & 5 \\
\hline Knowledge management & 4 \\
\hline Libraries & 4 \\
\hline Information organization & 3 \\
\hline Organization of knowledge & 3 \\
\hline Subject Access & 3 \\
\hline Authorship & 2 \\
\hline Cataloging codes & 2 \\
\hline Cross-cultural studies & 2 \\
\hline Dewey decimal classification & 2 \\
\hline Feminism & 2 \\
\hline Library and information science & 2 \\
\hline
\end{tabular}

Tabla II. Palabras clave en los artículos de Olson

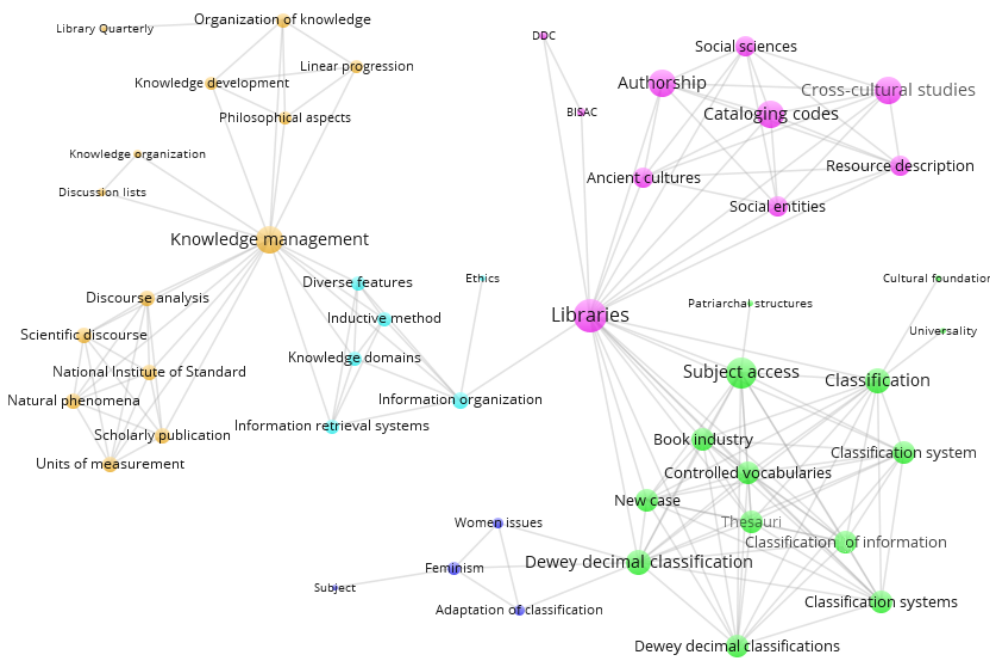

Figura 6. Red semántica Olson
3.4. Red semántica de los artículos que citan a Olson 2000-2015

Se hallaron 177 artículos que citan alguno de los artículos de Olson publicados entre 2000-2015 en Scopus, de los cuales se identificaron 574 palabras clave, de las que 472 se utilizaron una sola vez y 59 en, al menos, dos artículos. A continuación, se presenta la Tabla III de las palabras que recurrieron tres o más veces en los artículos:

\begin{tabular}{|c|c|c|c|c|c|}
\hline Palabras clave & fi & Palabras clave & $\begin{array}{l}f \\
i\end{array}$ & Palabras clave & $\begin{array}{l}f \\
i\end{array}$ \\
\hline Classification & $\begin{array}{l}1 \\
6\end{array}$ & Semantic web & 5 & $\begin{array}{l}\text { Information } \\
\text { management }\end{array}$ & 3 \\
\hline $\begin{array}{l}\text { Knowledge } \\
\text { management }\end{array}$ & $\begin{array}{l}1 \\
3\end{array}$ & Digital libraries & 4 & $\begin{array}{l}\text { Information } \\
\text { retrieval } \\
\text { systems }\end{array}$ & 3 \\
\hline $\begin{array}{l}\text { Knowledge } \\
\text { organization }\end{array}$ & $\begin{array}{l}1 \\
2\end{array}$ & Indexing & 4 & Internet & 3 \\
\hline $\begin{array}{l}\text { Information } \\
\text { retrieval }\end{array}$ & 9 & $\begin{array}{l}\text { Information } \\
\text { systems }\end{array}$ & 4 & $\begin{array}{l}\text { Knowledge } \\
\text { representation }\end{array}$ & 3 \\
\hline $\begin{array}{l}\text { Indexing (of } \\
\text { information) }\end{array}$ & 8 & Ontology & 4 & library services & 3 \\
\hline $\begin{array}{l}\text { Information } \\
\text { science }\end{array}$ & 8 & article & 3 & Methodology & 3 \\
\hline Libraries & 8 & Bias & 3 & $\begin{array}{l}\text { Philosophical } \\
\text { aspects }\end{array}$ & 3 \\
\hline $\begin{array}{l}\text { Classification of } \\
\text { information }\end{array}$ & 7 & $\begin{array}{l}\text { controlled } \\
\text { vocabularies }\end{array}$ & 3 & $\begin{array}{l}\text { PUBLIC } \\
\text { libraries }\end{array}$ & 3 \\
\hline Design & 6 & culture & 3 & Search engines & 3 \\
\hline Ethics & 6 & $\begin{array}{l}\text { Dewey decimal } \\
\text { classifications }\end{array}$ & 3 & Semantics & 3 \\
\hline $\begin{array}{l}\text { Information } \\
\text { organization }\end{array}$ & 6 & Education & 3 & Students & 3 \\
\hline Social tagging & 6 & human & 3 & Teaching & 3 \\
\hline Thesauri & 6 & $\begin{array}{l}\text { Indexing } \\
\text { language }\end{array}$ & 3 & $\begin{array}{l}\text { Theoretical } \\
\text { foundations }\end{array}$ & 3 \\
\hline Cataloging & 5 & $\begin{array}{l}\text { Indigenous } \\
\text { knowledge }\end{array}$ & 3 & Web 2.0 & 3 \\
\hline $\begin{array}{l}\text { Classification } \\
\text { system }\end{array}$ & 5 & & & & \\
\hline
\end{tabular}

Tabla III. Palabras clave en artículos que citan a Olson

La red generada es densa, como se ve en la Figura 7 , para obtener una gráfica más clara se eliminaron las palabras clave que tuvieran relación con menos de veintiún nodos. Para obtenerla se creó una partición de grado ejecutando network/create partition/degree/all, luego se extrajeron las palabras con operation/network+partition/extrac subnetwork. Además, para que el programa identificara los nodos que hacen parte de un mismo espacio temático por sus relaciones mutuas, se ejecutó en Pajek la ruta: Network/create partition/communities/Louvain Method/Multi-level coarsening+multi-level refinement, con un parámetro de resolución de ' 1 '. El resultado se exportó al programa VOSviewer y como resultado se obtuvo la Figura 8. 


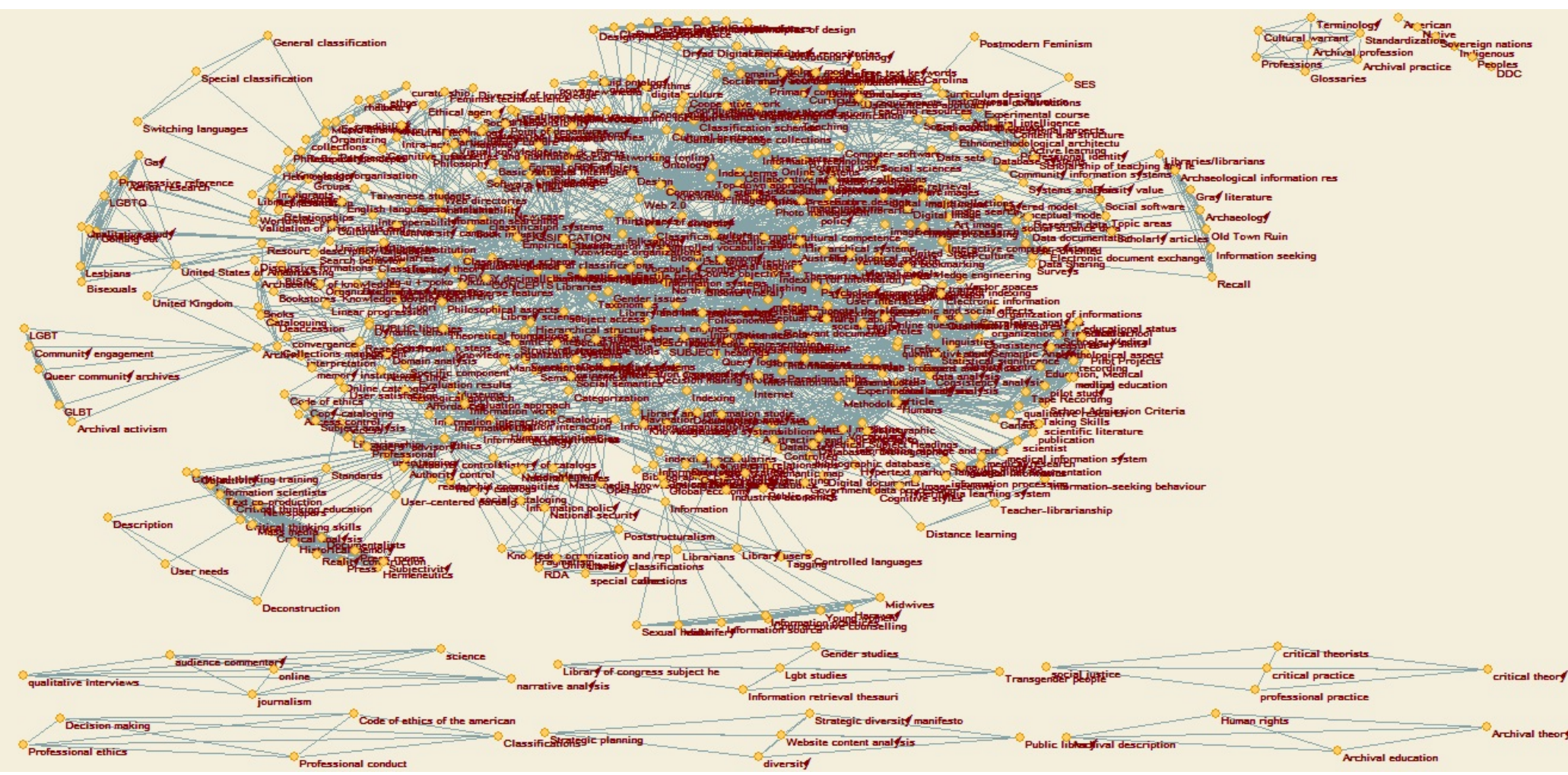

Figura 7. Red semántica Total de artículos que citan a Olson

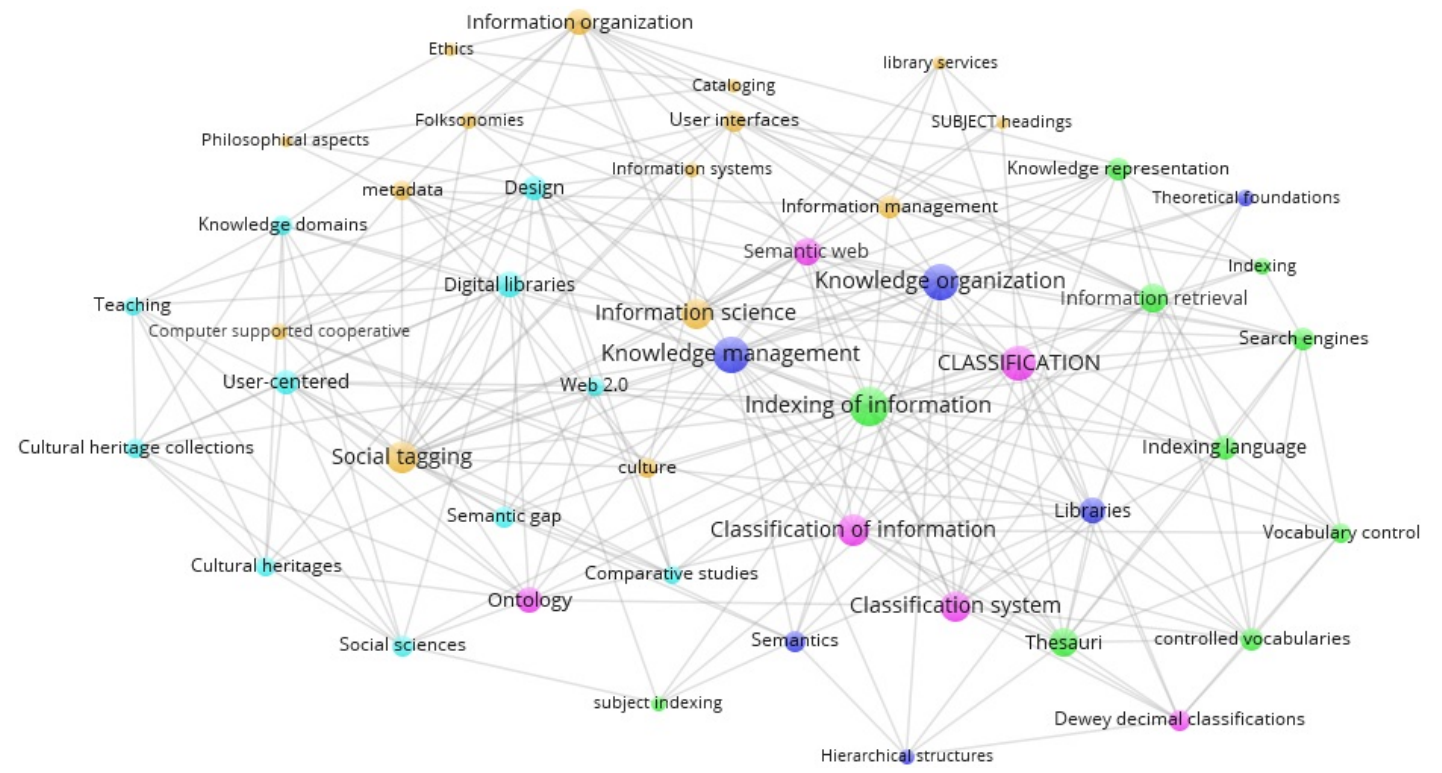

Figura 8. Red semántica de artículos que citan a Olson

\section{Conclusiones}

El estudio de la obra de Hope A. Olson, mediante la aplicación de la metodología CAMEO con la asistencia del programa Pajek arrojó resultados esperados, debido al conocimiento previo de su obra, pero permitió dilucidar aspectos de suma importancia para comprender sus aportes teóri- cos al campo de la clasificación desde una perspectiva crítica y subjetivista, concentrando gran parte de su trayectoria al estudio sistemático de la DDC, por sus siglas en inglés, Dewey Decimal Classification y su impacto en la cultura a través de las bibliotecas, especialmente las estadounidenses. Para ello, Olson recurre a referentes conceptuales propios del campo, su referente 
más común son sus propios trabajos, de la producción que hizo parte de la muestra de este estudio. Olson se citó a sí misma 47 veces, lo que significa que en cada artículo cita aproximadamente 1.8 de sus artículos, como única autora o coautora, empero el resultado no es sorprendente, porque debido a la originalidad y unicidad de sus trabajos académicos es imperativo que recurra a sus propios comentarios para dar suelo firme a sus nuevas acepciones sobre clasificación y organización del conocimiento.

Luego, entre sus referencias más usuales se encuentran dos clásicos de la clasificación: Dewey y Cutter. Sobre el primero, sus referencias son a la DDC, sus comentarios a la clasificación bibliográfica más ampliamente traducida y usada en el mundo, se enfoca en las implicaciones de los números que empleados para la representación de los grupos sociales y culturas históricamente marginalizados en la clasificación en cuestión, así como en los vocabularios controlados utilizados en el proceso de la indización, especialmente el LCSH. Olson indaga específicamente por el lugar/notación del feminismo entre las notaciones de la clasificación y compara recurrentemente las denominaciones asignadas a las teorías feministas y a la mujer, ambos como conceptos, en los vocabularios controlados más populares en contraste con algunos más específicos como el Women's Thesaurus y Canadian Feminist Thesaurus. En la DDC, Olson encuentra pobremente representadas las teorías feministas y estudios sobre la mujer por la que propone en su artículo de 2003 Adapting Dominant Classifications to Particular Contexts publicado en Knowledge Organization and Classification in International Information Retrieval, la creación de una base de datos y herramientas de acceso para solucionar lo que Olson percibe como un problema de representación, para la base de datos Olson y sus coautoras tipifican el tipo de información contenida en: Vocabularios, una mixtura entre Índice Dewey y el Women's Thesaurus; las notaciones de la DDC enlazadas al tesauro y las nuevas notaciones de la DDC, nuevamente relacionadas con términos del tesauro ya mencionado. Las herramientas de acceso o herramienta de acceso es un software sobre el que los autores dicen que debe funcionar con una licencia en abierto que permite tener un software barato y cooperativo, por lo tanto ampliamente accesible y cualificable. La propuesta se sintetiza así: Olson y las autoras proponen una expansión a la DDC relacionándola con el tesauro a fin de representar el feminismo y los estudios sobre la mujer sobrepasando el nivel meramente crítico al presentar una solución metodológica viable y posible, sin embargo se queda en nivel de prototipo porque no hay respuesta o réplicas aún identificadas.
A lo largo de su trabajo, Olson no sólo se refiere a la DDC, sino a las clasificaciones en general como representaciones caprichosas que se rigen bajo los principios de universalidad y exclusividad o jerarquía (2002, pp. 382-385), cuyo objetivo es organizar el universo bibliográfico y documental, de modo que define límites para unir y separar en razón de la similitud y diferencia entre conocimiento para asignarle un número o notación unívoca para ser recuperado de un sistema de información. El disgusto de Olson no es la DDC, aunque se enfoque principalmente en ella; el malestar de Olson es que bajo los principios que rigen las clasificaciones, estas fortalecen la parcialidad en favor de algunos grupos sociales representándolos con mayor fuerza en los sistemas de organización del conocimiento. Como oposición usa a Browker y Star (2002, 389 p.) que proponen tres consideraciones al momento de diseñar una clasificación para favorecer la neutralidad: reconocer la polifonía de voces, ser sensible con las exclusiones y reconocer la clasificación como una actividad de balance, de modo que la iniciativa de Olson es el solapamiento de las clasificaciones y vocabularios controlados para ampliar los límites creados bajo los principios de universalidad y jerarquía.

Las disertaciones de Olson sobre Cutter no varían mucho en relación con los comentarios a Dewey, de manera consistente critica la ubicuidad del principio de jerarquía presente en ambas clasificaciones, con la diferencia de que para Cutter, además de la lógica, el absurdo podría servir para estructurar la clasificación, de una parte la estructura lógica facilita la creación de un orden más eficaz. Para Cutter, lógica y absurdo son necesarios para la organización por lo que acepta la dualidad como principio y lo materializa con la creación del catálogo diccionario, en él ideó una organización por entradas estructuradas jerárquicamente incluyendo referencias cruzadas, es decir, aceptando la lógica y el absurdo (2004, pp. 605-606).

Después de los tres referentes conceptuales ya mencionados, Olson usa los aportes de la profesora de la Universidad de Michigan, Karen Markey, en el campo de indización, las contribuciones del profesor de la Universidad de Tennessee, Bharat Mehra, sobre la justicia social aplicada a las bibliotecas y los estudios culturales, y el trabajo del profesor de la School of Information de Berkeley, Geoffrey Nunberg, con su trabajo sobre el concepto de información y su historia. Sobre esto se puede concluir que los principales referentes de Olson son de origen norteamericano (por la afiliación institucional de los autores mencionados), los cinco desarrollaron y desarrollan su trabajo en Estados Unidos denotando que 
aunque Olson se contrapone a una visión clásica de la clasificación, está sujeta a una escuela clásica, aunque renovada, de la bibliotecología.

Los demás referentes de Olson incluyen colegas de la Universidad de Milwaukee como Kipp y Smiraglia, autores clásicos de la bibliotecología como Ranganathan, Don Swanson, Cyril Cleverdon, Elaine Svenonius, entre otros, y autores generales como los filósofos franceses Foucault y Derrida.

Del rastreo hecho en Scopus se hallaron 212 citas, en las que predominó Olson como principal citadora de su trabajo. De manera independiente y en coautoría, Daniel Martínez Ávila es el segundo; y Guimarães el tercero. El trabajo de los tres autores está estrechamente relacionado porque sus inquietudes son similares, incluso como se puede ver en la Figura 3, el centro de la red es la relación entre Guimarães-Olson-Martínez, por lo que se puede deducir que entre estos autores hay una fuerte conexión temática que podría calificarse como un colegio invisible. Esta idea se reafirma en las Imágenes 4 y 5 , en la que se pueden ver los enlaces de coautoría entre los autores.

En la Figura 3 también se pueden detallar tres triadas relevantes que podrían sumarse al colegio invisible como periferias, la triada Olson-Martínez-Kipp, la triada Olson-Milani- Guimarães y la triada Olson-Martínez-San Segundo. Las trataremos con mayor detalle: en la primera se relacionan la autora focal con Kipp que es una colega directa de Olson y Martínez-Ávila que es el segundo citador de los trabajos de la autora. Lo común entre estos autores es que en algún momento han trabajado en un grupo de investigación que dirigió Olson durante su tiempo como profesora activa de la Universidad de Milwaukee. Actualmente, Kipp es profesora asistente en la Universidad y Martínez-Ávila ha sido pasante de investigación en la alma mater de Olson. En la segunda tríada Olson-Milani- Guimarães se demuestra el impacto de Olson en el ámbito bibliotecológico brasilero, concretamente en los estudios desarrollados en la Universidad Estatal Paulista y, la tercera triada Olson-Martínez-San Segundo representa el impacto de Olson en las investigaciones de autores españoles siendo baja respecto a la representación brasilera. También podría sumarse a esta última tríada las citas por parte de Antonio García Gutiérrez, sin embargo, este autor sólo está relacionado con Martínez.

De las relaciones presentadas, además de Olson como autora central de la red egocéntrica, destaca la importancia de Martínez-Ávila que juega como inmediación entre los autores brasileros y españoles, por lo que es valioso destacar su papel en la difusión del trabajo de Olson en ambos escenarios y su esfuerzo por ensanchar el campo de clasificación a partir de los postulados escritos por Olson durante su trayectoria académica.

A modo de resumen, el impacto de Olson se localiza en Brasil, Estados Unidos, Canadá, España e India, este emplazamiento se fijó a partir de la formación académica de los citadores, que además permite determinar las instituciones de estos países que acogen la obra de Olson: en Brasil es la Universidad Estatal Paulista, en Estados Unidos son la Universidad de Milwaukee y la Universidad de Wisconsin, en Canadá la Universidad de Alberta y la Universidad de Ontario, en España la Universidad Carlos III de Madrid y en India la Universidad Guru Nanak Dev.

EI CAMEO de coautoría coincide considerablemente con el CAMEO de citación, de los dieciocho coautores de Olson, ocho hacen parte de los principales citadores de Olson, a saber: Daniel Martínez-Ávila (3), Dietmar Wolfram (2), Margaret Kipp (2), Rosa San Segundo (1), Raina Bloom (1), Suellen Milani (1), Lisa M. Given (1), Jose Augusto Guimarães (1).

Los coautores de Olson que no se ubicaron entre los principales citadores de Olson, sí la citan, pero debido a su número reducido de publicaciones en las que citaron algún trabajo de la autora no quedaron representados en la Figura 3, estos coautores son: Hur-Li Lee (4), Richard Smiraglia (2), Steven J. Miller (2), Dennis Ward (2), Melodie J. Fox (1), Angela Kublik (1), Virginia Clevete (1), Suzana Ahmad (1), Bharat Mehra (1), Lei Zhang (1).

Estos diez coautores confirman, como se mencionó en el apartado anterior, que el impacto de Olson se localiza en países específicos, en este caso sus colaboraciones coinciden con los países mencionados, Estados Unidos y Canadá, porque Lee, Smiraglia, Miller, Ahmad, Fox y Bharat están afiliados en calidad de profesores y/o investigadores a universidades norteamericanas y Ward, Kublik, Clevete y Zhang a universidades canadienses. En ambos casos los coautores de Olson son del campo de la ciencia de la información, con énfasis en clasificación, ontologías, indización, metadatos, entre otros. Olson no tiene colaboraciones con investigadores de áreas diferentes a las de la ciencia de la información, cabe aclarar que es posible que las tenga y no estén incluidas en la colección de Scopus por lo que se ignora tal aspecto.

El trabajo de Olson, de acuerdo con la indización temática de sus publicaciones en Scopus, se encamina capitalmente por la clasificación, de igual manera la indización temática de las publicaciones que citan los trabajos de Olson también se 
enfocan mayoritariamente en la clasificación, como asunto cardinal de la publicación.

El segundo tema más común entre las publicaciones de Olson y las publicaciones de sus citadores es "Knowledge Managment" que en español se traduce como gestión del conocimiento. Es sorprendente, porque en el trabajo de Olson tal enfoque no es fundamental, sin embargo, mediante el análisis de las palabras claves, el término reluce como el segundo más tratado.

Los demás temas encontrados son irrebatibles, entre ellos: Information organization, Organization of Knowledge, Subject access, Cataloging codes, DDC, Feminism, Library Science, entre otros. Estas materias distinguen el enfoque de Olson y caracterizan su trayectoria, por lo que es frecuente que los términos que predominan en la red semántica de sus citadores sean Knowledge organization, Classification of information, Libraries, Social tagging, Cataloging, Semantic web, Ontology, entre otros, que pueden ser vistos en la Tabla 3, Figura 7 y Figura 8, lo que implica que el impacto del trabajo de Olson se ha extendido a áreas distintas y conexas a la clasificación.

Las contribuciones de Olson son sobresalientes, por la originalidad y criticismo con los que examina el campo matricial de la OC, la clasificación.

\section{Notas}

Existen otros estudios métricos sobre el trabajo de Olson, se recomienda la revisión complementaria de D. Wolfram (2016).

\section{Apéndice 1. Bibliografía de Hope A. Olson}

Given, L. M.; Olson, H. A. (2003). Knowledge organization in research: A conceptual model for organizing data. // Library and Information Science Research. 25:2, (Summer 2003) 157-176.

Lee, H.-L.; Olson, H. A. (2005). Hierarchical navigation: An exploration of yahoo! Directories. // Knowledge Organization. 32:1 (Enero 2005) 10-24.

Martińez-Ávila, D.; Kipp, M. E. I.; Olson, H. A. (2012). DDC or BISAC: The changing balance between corporations and public institutions. // Knowledge Organization. 39:5 (2012) 309-319.

Martínez-Ávila, D.; Olson, H. A.; Kipp, M. E. I. (2012). New roles and global agents in information organization in Spanish libraries. // Knowledge Organization. 39:2, 125-136.

Martínez-Ávila, D.; Segundo, R. S.; Olson, H. A. (2014). The use of BISAC in libraries as NEW cases of reader-interest classifications. // Cataloging and Classification Quarterly, 52:2 (January 2014) 137-155.

Mehra, B.; Olson, H. A.; Ahmad, S. (2011). Integrating diversity across the LIS curriculum: An exploratory study of instructors' perceptions and practices online. // IFLA Journal. 37:1 (Marzo 2011) 39-51.

Milani, S. O., Guimarães, J. A. C.; Olson, H. A. (2014). Bias in subject representation: Convergences and divergences in the international literatura. // Babik W. (Ed.), Advances in Knowledge Organization. Polland: International Society for Knowledge Organization, 2014. 335-342.
Miller, S. J.; Fox, M. J.; Lee, H.-L.; Olson, H. A. (2006). Great expectations: Professionals' perceptions and knowledge organization curricula. // In Advances in Knowledge Organization. Vienna: International Society for Knowledge Organization, 2006. 349-358.

Miller, S. J., Lee, H.-L., Olson, H. A.; Smiraglia, R. P. (2012). Online cataloging education at the University of Wisconsin-Milwaukee. // Cataloging and Classification Quarterly, 50:2-3 (January 2012) 110-126.

Olson, H. (2007). Cultural infrastructure: The story of how classification came to shape our lives. // Annual Advances in Classification Research Online. 18. http://www.scopus .com/inward/record.url?eid=2-s2.0-84870023860\& partnerlD $=40 \& \mathrm{md} 5=$ ef860544f7342a3e008a9793c1c3eaff

Olson, H. A. (2001). Patriarchal structures of subject access and subversive techniques for change. // Canadian Journal of Information and Library Science. 26:2-3 (June 2001) 26-29.

Olson, H. A. (2001). Sameness and difference a cultural foundation of classification. // Library Resources and Technical Services. 45:3 (January 2001) 115-122.

Olson, H. A. (2001). The power to name: Representation in library catalogs. // Signs. 26:3 (Springs 2001) 639-668.

Olson, H. A. (2002). Classification and universality: Application and construction. // Semiotica. 139 (March 2002) 377-391.

Olson, H. A. (2004). The ubiquitous hierarchy: An army to overcome the threat of a mob. // Library Trends. 52:3 (Winter 2004) 604-616.

Olson, H. A. (2006). Codes, costs, and critiques: The organization of information in Library Quarterly, 1931-2004. // Library Quarterly. 76:1 (January 2006) 19-35.

Olson, H. A. (2007). How we construct subjects: A feminist analysis. // Library Trends. 56:2 (Fall 2007) 509-541.

Olson, H. A. (2008). Wind and rain and dark of night: Classification in scientific discourse communities. // Advances in Knowledge Organization. Montreal: ISKO. 235-241.

Olson, H. A. (2009). Introduction to the special issue on the ethics of information organization. // Cataloging and Classification Quarterly, 47:7 (2009) 609-611.

Olson, H. A. (2010). Earthly order and the oneness of mysticism: Hugh of saint victor and medieval classification of wisdom. // Knowledge Organization. 37:2 (2010) 121137.

Olson, H. A. (2010). Hegel's epistemograph, classification, and Spivak's postcolonial reason. // Advances in Knowledge Organization. Rome: International Society for Knowledge Organization, 2010. 23-30.

Olson, H. A.; Wolfram, D. (2008). Syntagmatic relationships and indexing consistency on a larger scale. // Journal of Documentation. 64:4 (2008) 602-615.

Smiraglia, R. P., Lee, H.-L.; Olson, H. A. (2011). Epistemic presumptions of authorship. // ACM International Conference Proceeding Series. http://doi.org/10.1145/1940761. 1940780

Wolfram, D., Olson, H. A.; Bloom, R. (2009). Measuring consistency for multiple taggers using vector space modeling. // Journal of the American Society for Information Science and Technology, 60:10 (October 2009) 1995-2003.

Zhang, L.; Olson, H. A. (2015). Distilling abstractions: Genre redefining essence versus context. // Library Trends, 63:3 (Winter 2015) 540-554.

Kublik, A., Clevette, V., Ward, D.; Olson, H. A. (2013). Adapting dominant classifications to particular contexts. Knowledge organization and classification in international information retrieval. // Library and Information Science Research, 25:2 (2013) 13-32. 



\section{Procedimiento de evaluación}

Evaluation process

\section{Introducción}

El procedimiento de evaluación en Scire es el de revisión por pares mediante el sistema de doble ciego - los revisores no conocen el nombre de los autores, ni viceversa- semejante al de otras revistas científicas, aunque tiene algunas peculiaridades que permiten ajustarlo a las condiciones específicas de su campo científico y de sus lectores.

\section{Objetivos}

El objetivo del procedimiento de evaluación es que se puedan admitir con rapidez los trabajos buenos, mejorar los que pueden ser susceptibles de aceptación —esto es, que, siendo interesantes, contienen errores o lagunas que deben ser corregidas-y rechazar los que no son adecuados para la revista por su tema o calidad, redirigiéndolos hacia otras publicaciones adecuadas o haciendo sugerencias al autor para la posible reutilización y reorientación de su trabajo.

El procedimiento de revisión tiene que tener en cuenta a los autores de los artículos que revisa, con los que el revisor debe intentar ser justo, pero también debe responder ante los lectores y los demás autores que compiten por el espacio de la revista, así como, de forma más general, con el proyecto editorial, la propia comunidad científica y el conjunto de la sociedad.

\section{Procedimiento}

Cada artículo requiere al menos la opinión favorable de al menos dos revisores y cada nota breve de al menos uno. Si el director de la revista estima que el artículo entra dentro de los objetivos de Scire -que se encuentran públicamente disponibles en cada número y en la página web de la revista-, lo envía a dos revisores - o, si es necesario, a más- elegidos por el director. Los evaluadores pueden ser miembros del consejo científico, revisores propuestos por los miembros del consejo científico con anterioridad o con motivo del artículo en cuestión, o científicos de reconocido prestigio propuestos por el autor o autores del artículo. La elección se hace según su conocimiento del tema y el número de trabajos que han evaluado hasta el momento (para equilibrar la carga de trabajo entre ellos).
Si el director estima sin lugar a dudas que el tema del artículo no se adecua al de la revista, se lo comunica al autor con una explicación suficiente, y, si le es posible, le sugiere otra revista que pueda ser más adecuada. De esta forma, se ahorra tiempo del autor y de los revisores.

La agilidad del procedimiento de revisión es un aspecto fundamental, por lo que el director solicita a los revisores que envíen su valoración en dos semanas, y que, en caso contrario, renuncien expresamente al proceso de revisión. Sin embargo, si el revisor no realiza ninguna de estas acciones, el proceso se retrasa sin remedio. En este sentido, el autor debe tener en cuenta que el proceso de revisión tiene un carácter voluntario. La decisión de aceptar el trabajo depende, salvo en casos excepcionales, de la opinión de los revisores. En los casos en que no están de acuerdo, la decisión es tomada por el director de la revista, que, excepcionalmente, puede decidir enviar el artículo a un nuevo revisor.

\section{Criterios de evaluación}

Se solicita a cada revisor que indique su valoración sobre los siguientes aspectos en una escala del 1 al 5 ( 1 muy cuestionable, 2 marginal, 3 suficiente, 4 sólido, 5 excelente):

1. Tipo de contribución: Se indica si se trata de una contribución de tipo teórico o metodológico, un estado de la cuestión, una comunicación de resultados de investigación, una experiencia específica, una exposición con valor introductorio o docente sobre el tema o una noticia de interés. Si es una mezcla de varios tipos, es posible marcar más de uno.

2. Adecuación del tema de la revista: Aunque al enviar el artículo al revisor el director de la revista ya ha realizado un juicio sobre su adecuación al enfoque de la revisa Scire, el revisor puede también valorar este aspecto, comparando el tema del artículo con la declaración de objetivos y alcance de la revista, disponible en cada número y en la página web.

3. Interés e importancia del tema: Grado en el que el artículo aborda una cuestión de gran interés para el área científica de Scire, ya sea tradicionalmente, en el momento actual o en el futuro previsible. 
4. Actualidad del tema: Grado en el que el tema se sitúa en los frentes actuales de investigación. No es un aspecto imprescindible, pero sí se considera informativo.

5. Novedad y originalidad teórica de la aportación: Grado en el que el artículo aporta una novedad teórica a su campo de investigación; esto es, un nuevo problema, un nuevo enfoque, un nuevo modelo, una nueva relación o ley, una nueva hipótesis, un nuevo concepto o una interpretación o modificación original de otros anteriores. Debe tratarse lógicamente de una aportación relevante y fundamentada.

5. Novedad y originalidad metodológica de la aportación: Grado en el que el artículo aporta una novedad metodológica a su campo de investigación; esto es, un nuevo procedimiento de estudio, de análisis o de prueba, aunque sea a un problema conocido.

7. Aplicabilidad práctica: Grado en el que las ideas del artículo pueden servir para la mejora de procedimientos y actividades prácticas y, en definitiva, para el desarrollo y la innovación.

8. Rigor metodológico y validez de los resultados: Grado de coherencia, exactitud, precisión y cuidado con el que se aborda el tema de estudio; validez y actualidad de la metodología utilizada; rigor en la selección de las muestras y en la aplicación de la metodología a las mismas; grado de replicabilidad del estudio.

9. Rigor en el estado de la cuestión y el reconocimiento del trabajo previo: Hasta qué punto se ha realizado un estado de la cuestión suficiente y actualizado y se han manejado las referencias pertinentes para el problema abordado.

10. Claridad expresiva, orden y facilidad de lectura: El artículo debe estar redactado de forma clara y bien ordenada, sin redundancias ni ideas fuera de contexto; y debe ser fácilmente entendible por cualquier lector potencial de Scire. No debe faltar información necesaria ni deben existir lagunas sobre el problema abordado, el método, los resultados, la discusión, las conclusiones o las recomendaciones. Si el artículo contiene aparato matemático, debe ser comprensible por un lector no especialista.

11. Adecuación de gráficos, ilustraciones, tablas $y$ apéndices: Los gráficos, ilustraciones, tablas y apéndices deben ser necesarios y relevantes, estar bien resueltos técnicamente y disponer de una leyenda suficientemente explicativa.

13. Conformidad de las referencias a las normas de la revista: Grado en el cuál las referencias del artículo son suficientes y se conforman a las normas de la revista Scire.

\section{Familiaridad del revisor con el tema}

Aunque el director de la revista envía los artículos para su revisión intentando que coincidan con el campo de especialidad del revisor, pueden producirse desajustes. El revisor puede rechazar la revisión sugiriendo o no un revisor alternativo, o puede efectuar la revisión indicando de 1 (mínimo) a 5 (máximo) su grado de familiaridad con el tema del artículo evaluado. Si no rellena esta información, se entenderá que su grado de familiaridad es alto (4) o muy alto (5).

Esta información sirve para que el director de la revista pueda estimar la necesidad de enviar el artículo a un nuevo revisor en caso de conflicto de pareceres entre los revisores.

\section{Valoración final}

El revisor puede realizar cinco tipos de propuestas finales:

1. Aceptar el artículo para su publicación sin restricciones ni cambios, porque es un trabajo de alta calidad.

2. Aceptar el artículo para su publicación una vez realizadas las correcciones indicadas, bien sea incondicionalmente, al ser un trabajo de calidad, o bien de forma condicionada a que haya espacio disponible en el número, por ser un trabajo de calidad marginal. Las correcciones solicitadas se indican en las instrucciones para el autor, son de carácter menor y su comprobación puede ser delegada en el comité editorial.

3. Someter a reevaluacion el artículo una vez realizadas las correcciones indicadas en las instrucciones para el autor, porque son de importancia y amplitud, y deben ser comprobadas por el revisor original u otro revisor.

4. Rechazar el artículo por las razones indicadas en las instrucciones para el autor, donde el revisor especificará con claridad y amabilidad las razones por las que su trabajo debe ser rechazado $y$, si le resulta posible, realizará sugerencias sobre su mejora o lugares alternativos de publicación.

5. El revisor rechaza evaluar el artículo por su falta de familiaridad con el tema o por razones que especifica en los Comentarios confidenciales para el equipo directivo.

La labor de los revisores es fundamental para que una publicación científica realice su labor de manera adecuada. Scire agradece de forma muy especial el tiempo y esfuerzo que dedican, y reconoce su trabajo publicando periódicamente sus nombres. 


\title{
Instrucciones para la presentación de trabajos
}

\author{
Instructions for authors
}

\section{Cuestiones generales}

Scire admite artículos con estados de la cuestión, discusiones de carácter teórico y metodológico, e informes de investigación sobre proyectos terminados, así como noticias sobre proyectos en curso, experiencias, notas y reseñas, que traten de la representación, normalización, tratamiento, recuperación y comunicación de la información y el conocimiento.

Las lenguas de publicación de Scire son el español, el inglés y el portugués.

Los artículos son sometidos a proceso de revisión por pares según el sistema de doble ciego, aunque los autores pueden proponer revisores libremente. El procedimiento es público, y puede ser leído en el apartado anterior a las instrucciones.

Los autores se comprometen a presentar y discutir públicamente y presencialmente sus trabajos en el congreso Scire correspondiente al año en curso.

Los trabajos deben ser originales y tendrán una extensión máxima de 20.000 caracteres en el caso de los artículos; 12.000 caracteres para los estudios de caso; y 6.000 caracteres para las noticias, proyectos en curso, experiencias, notas y reseñas. Excepcionalmente, estas cifras podrán ajustarse en virtud del interés del trabajo, aunque siempre con el acuerdo previo del editor.

Los autores deben presentar en una hoja aparte sus datos personales completos: nombre, cargo, dirección, teléfono, fax y correo electrónico.

Los artículos han de presentarse en un documento Word o RTF debidamente maquetados según la plantilla disponible en www.ibersid.org con su gráficos incluidos. Irán precedidos de sus títulos, resúmenes informativos y palabras clave, todos ellos en inglés y español. Se incluirán en ficheros aparte los gráficos e imágenes en su archivo fuente para su eventual tratamiento, $y$, en cualquier caso, con resolución de impresión.

Todos los apartados, incluidos las notas, referencias y apéndices irán numerados secuencialmente. Los subapartados — cuyos títulos serán claros y sintéticos - deberán tener la forma “1.1. ”, “1.2. “, “1.2.1. " y así sucesivamente. No numere los resúmenes en español y en inglés, ni los apartados de notas, agradecimientos y referencias. Evite un rango de encabezamientos superior a tres.

No se deben relatar datos analíticos repetitivos $\mathrm{ni}$ elencos de recursos en el texto principal. Por favor, preséntelos en forma de tablas 0 , si fuera imposible, en forma de apéndice.

El editor podrá realizar cambios de estilo para adecuar el trabajo a los requisitos de la revista.

Se recuerda al autor que la violación de derechos intelectuales y códigos éticos es un comportamiento inaceptable y puede constituir un grave delito.

\section{Formatos de texto}

No utilice subrayados, negritas ni versales.

Utilice mayúsculas sólo para acrónimos. No ponga puntos y espacios entre las letras que los forman.

Las cursivas se deben utilizar tan sólo para resaltar términos en otras lenguas, títulos de obras, palabras clave muy importantes que podrían servir a modo de títulos de un párrafo o conjunto de párrafos, y, con parquedad, para enfatizar los demás términos y frases a gusto del autor.

No utilice listas con salto de línea o de párrafo. Redacte párrafos completos según las reglas y los recursos gramaticales disponibles en su lengua de redacción. Puede indicar orden en las enumeraciones por medio de números o letras entre paréntesis, como, por ejemplo, (1), (2)...

\section{Figuras y gráficos}

Las figuras deben presentarse también en ficheros aparte en formato EPS o PDF con resolución de impresión de alta calidad (600 ppp) y, además, en el formato de la aplicación original con la que se creó. Tenga cuidado si genera imágenes a partir de la pantalla de su ordenador. Si recurre a imprimir pantalla en Windows obtendrá solo una resolución de 72 ppp. En ese caso, utilice una pantalla lo más grande posible, amplíe la ventana al máximo, copie con la tecla "impr pant", pegue en el programa "Paint" y guarde el fichero; compruebe luego los resultados. Existen programas que permiten obtener imágenes de pantalla 
a una resolución aceptable. En el cuerpo del artículo las imágenes portarán epígrafes indicativos de su contenido precedidos de la palabra "Figura" y un número correlativo (por ejemplo, "Figura 1. ").

\section{Tablas}

Deben realizarse con el mismo procesador de textos que el artículo. En texto portarán epígrafes indicativos de su contenido precedidos de la palabra "Tabla" y un numeral romano correlativo (por ejemplo, "Tabla I. ").

\section{Notas}

Las notas explicativas deben usarse excepcionalmente. No utilice el sistema automático de su procesador de textos. Refiéralas en texto tecleando su número secuencial entre paréntesis, e inclúyalas al final del trabajo en un apartado titulado "Notas" situado inmediatamente antes del dedicado a las "Referencias", en orden secuencial y precedida cada una de ellas de su correspondiente número entre paréntesis seguido de tabulador. Las citas bibliográficas se realizarán como en el resto del texto; y la referencia completa se incluirá en el apartado de "Referencias". Las páginas web se consideran referencias bibliográficas y deben tratarse como tales, evitando su cita como nota.

\section{Citas bibliográficas en texto}

Las referencias bibliográficas en texto se denotarán por el apellido del autor, el año del trabajo y, si es necesario, el número de página. Si conviene, el nombre y el apellido del autor podrán quedar fuera del paréntesis. Si dos autores de la lista de referencias poseen el mismo primer apellido, se referirán por sus dos apellidos y, si tienen ambos apellidos iguales, por el nombre también. Si dos o más trabajos del mismo autor son del mismo año, se distinguirán mediante letras del alfabeto secuenciales en minúsculas pospuestas a la fecha sin espacio. Si hay varias referencias dentro del paréntesis, se separarán por punto y coma si son de diferentes autores, y coma si son del mismo.

Así, por ejemplo, "Es una teoría sustentada por varios autores (Gallego, 1975; Fernández y Alonso, 1993) [...]". "Según Jaime Pérez (1993, p. 24) se establecen [...]". "El mismo autor (Pérez, p. 27) hace constar la conveniencia de [...]". "Se han detectado diferencias en la replicación de la experiencia (Menéndez, 1994a, 1994b; Menéndez y Alonso, 1997)".

\section{Formato de las referencias bibliográficas}

Las referencias bibliográficas se incluirán por orden alfabético al final del artículo bajo el título "Referencias". Deberán seguir la norma UNE 50104:1996/ISO 690:1987, y, en cuanto a la puntuación, aproximarse lo más posible a las ISBD abreviadas, aunque sin espacio delante de punto, coma y punto y coma. Las referencias a páginas web deben incluirse también en este apartado, no en el texto ni en nota. Refiera adecuadamente en el texto del articulo toda la bibliografía utilizada; no incluya en el apartado referencias documentos que no haya incluido en el texto. Se presenta a continuación el formato para los principales tipos de materiales, con los elementos que pueden darse o no en cursivas, y seguidos de un ejemplo.

7.1. Monografías, congresos, informes, normas $\mathrm{y}$ tesis

Apellido, Nombre; ApellidoN, NombreN (función) (Año). Título: subtítulo. Edición. Lugar de publicación: editor; lugar de publicación: editor. ISBN número. Tesis doctoral.

Delclaux, Isidoro; Seoane, Julio (1982). Psicología cognitiva y procesamiento de la información: teoría, investigación y aplicaciones. Madrid: Ediciones Pirámide.

\subsection{Artículos de publicaciones periódicas}

Apellido, Nombre; ApellidoN, NombreN (función) (Año). Título: subtítulo. // Título de la publicación periódica. ISSN numero. Volumen:número, primera página-última página.

Ellis, David (1992a). The physical and cognitive paradigms in Information Retrieval Research. /I Journal of Documentation. 48:1, 45-46.

7.3. Capítulos de una monografía, de un informe o contribuciones a un congreso

Apellido, Nombre; ApellidoN, NombreN (función) (Año). Título: subtítulo. // Apellido, Nombre; ApellidoN, NombreN (función) (Año). Título: subtítulo. Edición. Lugar de publicación: editor; lugar de publicación: editor. ISBN número. Primera páginaúltima página.

Markey, Karen (1990). Keyword searching in an online catalog enhanced with a library classification. // Bengtson, Betty G.; Hill, Janet Swan (eds.). Classification of library materials: current and future potential for providing access. New York: Neal-Shuman Publishers. 99-125. 
Smith, Ph. J.; Beghtol, C.; Fidel, R.; Kwasnik, B. $H$. (eds.) (1993). Proceedings of the 4th ASIS SIG/CR Classification Research Workshop: Columbus, OH, Oct.24, 1993. Silver Spring, MD.: American Society for Information Science.

\subsection{Páginas web y recursos en línea}

Se tratarán como monografías, artículos o capítulos según corresponda y se añadirá al final detrás de punto el URL y la fecha de consulta entre paréntesis:

\section{Referencia. URL (Fecha de consulta).}

Sagredo Fernández, Félix; Espinosa Temiño, María Blanca (2000). Del libro, al libro electrónico-digital. // Cuadernos de Documentación Multimedia. 9 (2000). http://www.ucm.es/info/multi doc/multidoc/revista/num9/cine/sagredo.htm (2001-01-22).

\section{Apéndice I. El resumen}

Un resumen proporciona información sobre objetivos, alcance, metodología, resultados, conclusiones y recomendaciones. Por alcance se entiende la determinación de hasta qué punto se han tratado los objetivos. Los resultados, conclusiones y recomendaciones se distinguen unos de otros así: los resultados son las informaciones o datos específicos y concretos que se obtienen de la aplicación de la metodología; las conclusiones se derivan de los resultados bien al interpretarlos en el marco de conocimientos teóricos previos o bien al crear un marco de interpretación nuevo a partir de ellos a través de un proceso de abstracción; finalmente, las recomendaciones se refieren a los nuevos problemas y vías de estudio que plantean a la vista de los resultados y conclusiones.

El resumen se debe redactar de forma clara y concisa, sin redundancias ni perífrasis ni información difícil de interpretar, como neologismos o abreviaturas que no se desarrollan.

Es muy conveniente que su primera frase contenga en primer lugar la mención del tipo de documento. Por ejemplo, "Estado de la cuestión sobre la aplicación del modelo europeo de calidad a las bibliotecas universitarias", "Proyecto de aplicación del MARC21 a la catalogación de páginas web institucionales", etc.

\section{Apéndice II. La redacción del artículo científico: algunos aspectos obvios frecuentemente descuidados}

\subsection{Sistematicidad}

El artículo científico debe redactarse de forma muy organizada, con una estructura textual firme. En los informes de resultados de proyectos, se suele utilizar el esquema objetivos-metodologíaresultados- conclusiones- recomendaciones. En los estados de la cuestión se aborda el asunto en orden cronológico o bien sistemático, según la ontología propia del área científica en cuestión; sigue la discusión, la síntesis, las conclusiones y las recomendaciones. Los artículos críticos suelen seguir el esquema tesis-síntesis-antítesis. Otros tipos documentales pueden exigir otras estructuras textuales, pero, en cualquier caso, dicha estructura debe ser explícita y aparente.

\subsection{Claridad y concisión}

El lenguaje del artículo científico debe ser claro y conciso. Excepcionalmente, en los trabajos de tipo ensayístico las personas con un alto dominio del lenguaje escrito pueden permitirse la utilización de recursos literarios.

\subsection{Pertinencia y parsimonia}

Debe evitarse proporcionar información ya conocida, salvo si constituye el punto central de la discusión. A ella cabe referirse por medio de las citas o, si estas no son necesarias, suponerla patrimonio de la comunidad profesional y científica. Sistematizar conocimiento es una función que se realiza solo en un tipo de artículo científico - la revisión o estado de la cuestión-; en los demás casos es contraproducente, aunque se deben citar las fuentes y las obras clave en la introducción del trabajo.

\subsection{Civilidad}

Es necesario citar a otros autores que han trabajado sobre el tema, demostrando que se conoce la literatura previa y que el trabajo se inserta civilizadamente en un determinado contexto científico. 


\title{
Índice de autores
}

Author index

Cantisani, Mariana, 67

Dal'Evedove, Paula Regina, 35

Fernández-Molina, Juan-Carlos, 45

Ferreira, Verônica de Sá, 55

Fujita, Mariângela Spotti Lopes, 35

Gilchrist, Alan, 13

Guimarães, José Augusto Chaves, 45

Jorente, María José Vicentini, 67

Marco Cuenca, Gonzalo, 77
Martínez-Ávila, Daniel, 67

Nakako, Natália, 67

Pedraza Gracia, Manuel José, 23

Restrepo Fernández, María Camila, 91

Sales, Rodrigo de, 55

Salvador Oliván, José Antonio, 77

Santos, João Carlos Gardini, 45

Tartarotti, Roberta Cristina Dal'Evedove, 35

\section{Índice de materias en español}

\author{
Subject index in Spanish
}

Análisis de contenido, 35, 45

Análisis de dominio, 67

Bacon, Francis, 55

Bibliotecarios, 23

Big data, 77

Brasil, 35

Ciencia de la información, 13, 67

Clasificación de las artes, 55

Clasificación Decimal Dewey, 91

Clasificación documental, 91

CMBD, 77

Conjunto Mínimo Básico de Datos, 77

Datos en salud, 77

Diseño de la información, 67

Estado de la cuestión, 35

Gestión de la información sanitaria, 77

Harris, William Torrey, 55

Hegel, G. W. F., 55

Identificación, 23

Información, 45

Información jurídica, 45
Interdisciplinariedad, 67

Investigación, 35

Investigadores, 23

Lenguajes documentales, 91

Ley de acceso a la información, 45

Libros antiguos, 23

Olson, Hope A., 91

Organización de la información, 45

Organización del conocimiento, 55, 91

Prospectiva, 13

RAE-CMBD, 77

RDA, 23

Recuperación de la información, 13

Registro de Actividad de Atención Sanitaria Especializada, 77

SISNS, 77

Sistema de Información Sanitaria del SNS, 77

Sistemas de Información hospitalaria, 77

Tendencias, 13

Teoría de la clasificación, 55

Valoración, 23

\section{Índice de materias en inglés}

Subject index in English

Access to information act, 45

Arts classification, 55

Bacon, Francis, 55

Big Data, 77

Brazil, 35
Classification theory, 55

Content analysis, 45

Decimal Dewey Classification, 91

Domain analysis, 67

Harris, William Torrey, 55 
Health Data, 77

Health Information management, 77

Health Information System of the NHS, 77

Hegel, G. W. F., 55

History, 13

Hospital Information System, 77

Identification, 23

Indexing language, 91

Information, 45

Information design, 67

Information organization, 45

Information retrieval, 13

Information science, 13, 67

Interdisciplinarity, 67

Knowledge organization, 55, 67

Knowledge Organization, 91

Legal information, 45
Librarians, 23

Library classification, 91

MBDS, 77

Minimum Basic Data Set, 77

Olson, Hope A., 91

Prospective, 13

RAE-CMBD, 77

Rare books, 23

RDA, 23

Research, 35

Researchers, 23

SISNS, 77

Specialized Health Care Activity Register, 77

State of the art, 35

Subject analysis, 35

Trends, 13

Valuation, 23 